Arq. Bras. Med. Vet. Zootec., v.58, n.3, p.440-446, 2006

\title{
Qualidade microbiológica do leite refrigerado nas fazendas
}

\author{
[Microbiological quality of refrigerated milk on farms] \\ E.F. Arcuri ${ }^{1}$, M.A.V.P. Brito ${ }^{1}$, J.R.F. Brito ${ }^{1}$, S.M. Pinto $^{1,2}$, F.F. Angelo ${ }^{1}$, G.N. Souza ${ }^{1}$ \\ ${ }^{1}$ Embrapa Gado de Leite \\ Rua Eugênio do Nascimento, 610 \\ 36038-330 - Juiz de Fora, MG \\ ${ }^{2}$ Bolsista CNPq
}

\begin{abstract}
RESUMO
Avaliaram-se a qualidade microbiológica do leite obtido mecanicamente e refrigerado durante 48 horas, em 24 rebanhos, e a associação entre a contaminação microbiana e os procedimentos de higienização dos equipamentos de ordenha e armazenamento do leite. Os procedimentos de higiene foram avaliados in loco com auxilio de questionários. Foram realizadas a contagem padrão em placas, a contagem de coliformes totais e a pesquisa de Staphylococcus aureus e Streptococcus agalactiae. No leite de 14 rebanhos, foram pesquisadas Salmonella spp. e Listeria monocytogenes. As médias geométricas da contagem padrão foram $<1,0 \times 10^{6} \mathrm{UFC} / \mathrm{ml}$ em $20 \mathrm{rebanhos}$, e $<7,5 \times 10^{5} \mathrm{UFC} / \mathrm{ml}$ em 19 . Onze rebanhos apresentaram contagem média de $<1,0 \times 10^{5} \mathrm{UFC} / \mathrm{ml}$. Contagens médias de coliformes $>10^{3} \mathrm{UFC} / \mathrm{ml}$ foram verificadas em sete rebanhos. $S$. aureus e $S$. agalactiae foram isolados em 22 e 12 dos 24 rebanhos, respectivamente, e não foram encontradas Salmonella spp. e L. monocytogenes. O uso de detergentes alcalino e ácido, mais o de sanitizante foi associado $(\mathrm{P}<0,05)$ à contagem padrão $<1,0 \times 10^{5}$, e o emprego de apenas um ou de nenhum produto foi associado a contagens $>5 \times 10^{5} \mathrm{UFC} / \mathrm{ml}$.
\end{abstract}

Palavras-chave: qualidade do leite, microbiologia, tanque de refrigeração, contagem padrão de bactérias

\begin{abstract}
The effect of bulk tank and milking machine cleaning procedures (determined from a questionnaire) on bacterial contamination of 48-hour refrigerated milk was examined in 24 herds. Milk samples were analyzed for standard plate count (SPC) and for total coliform, Staphylococcus aureus and Streptococcus agalactiae contamination. Milk samples from 14 herds were cultured for Salmonella and Listeria monocytogenes. Geometrical means of SPC were $<1.0 \times 10^{6} \mathrm{UFC} / \mathrm{ml}$ in $20 \mathrm{herds},<7.5 \times 10^{5} \mathrm{UFC} / \mathrm{ml}$ in 19 herds and $<1.0 \times 10^{5} \mathrm{UFC} / \mathrm{ml}$ in 11 herds. Geometrical means $>10^{3} \mathrm{UFC} / \mathrm{ml}$ of total coliforms were observed in seven herds. S. aureus and S. agalactiae were found in 22 and 12 herds, respectively. Salmonella and L. monocytogenes were not found in any of the samples. The use of alkaline and acid detergents plus sanitizing was associated $(P<0.05)$ with $S P C<1.0 \times 10^{5}$, and the use of either alkoline or acid detergent or sanitizing or no chemical product was associated with $\mathrm{SPC}>5.0 \times 10^{5} \mathrm{UFC} / \mathrm{ml}$.
\end{abstract}

Keywords: milk quality, microbiology, equipment cleaning procedure, standard plate count

Recebido em 8 de setembro de 2004

Aceito em 23 de setembro de 2005

E-mail: edna@cnpgl.embrapa.br

Apoio: Projeto Embrapa - PRODETAB 047-01/99 


\section{INTRODUÇÃO}

A disponibilidade de nutrientes no leite, sua alta atividade de água e seu $\mathrm{pH}$ próximo da neutralidade torna-o meio extremamente favorável ao crescimento microbiano.

No leite cru encontra-se uma diversidade de bactérias, incluindo as psicrotróficas, que podem se multiplicar a $7^{\circ} \mathrm{C}$ ou menos, independentemente de sua temperatura ótima de crescimento, as termodúricas, que podem sobreviver ao tratamento térmico da pasteurização, as láticas, que acidificam rapidamente o leite cru não-refrigerado, os coliformes e as bactérias patogênicas, principalmente as que causam mastite (Hayes e Boor, 2001). A ação das bactérias ou de suas enzimas sobre os componentes lácteos causa várias alterações no leite e seus derivados. Esses defeitos incluem sabores e aromas indesejáveis, diminuição da vida de prateleira, interferência nos processos tecnológicos e redução do rendimento, especialmente de queijos (Hicks et al., 1982; Champagne et al., 1994).

Muitas bactérias contaminantes do leite cru produzem enzimas extracelulares (proteases e lipases) termorresistentes, cuja atividade residual afeta a qualidade dos produtos finais, mesmo na ausência de células bacterianas viáveis (Muir, 1996; Chen et al., 2003). A contaminação bacteriana do leite cru pode ocorrer a partir do próprio animal, do homem e do ambiente. Exceto em casos de mastite, o leite ejetado apresenta baixo número de microrganismos, que não constituem riscos à saúde.

Do ponto de vista tecnológico, os microrganismos de maior importância são os que contaminam o leite durante e após a ordenha. Essa contaminação é variável, tanto qualitativa quanto quantitativa, em função das condições de higiene existentes (Froeder et al., 1985).

A temperatura e o período de armazenamento do leite antes da pasteurização determinam, de maneira seletiva e pronunciada, a intensidade de desenvolvimento das diversas espécies microbianas contaminantes. As temperaturas baixas inibem ou reduzem a multiplicação da maioria das bactérias e diminuem a atividade de enzimas degradativas.
A obtenção do leite de vacas sadias, em condições higiênicas adequadas, e o seu resfriamento imediato a $4^{\circ} \mathrm{C}$ são as medidas fundamentais e primárias para garantir a qualidade e a segurança do leite e seus derivados.

No Brasil, em anos recentes, tem-se adotado a coleta de leite a granel. Nesse sistema, o leite cru, armazenado em tanques de expansão a $4^{\circ} \mathrm{C}$ por até 48 horas, é transportado para a indústria em caminhão com tanque isotérmico. Recentemente, o Ministério da Agricultura, Pecuária e Abastecimento (MAPA) publicou a Instrução Normativa $\mathrm{n}^{\circ}$ 51, que estabelece o Regulamento Técnico de Produção, Identidade e Qualidade do Leite Tipo A, do Leite Tipo B, do Leite Tipo C e do Leite Cru Refrigerado (Brasil, 2002). No regulamento constam novos requisitos de qualidade, incluindo a contagem padrão de bactérias do leite. O limite máximo a ser aceito para o leite cru refrigerado, de produtores individuais das regiões Sul, Sudeste e CentroOeste foi estabelecido em 1.000.000 UFC/ml, com redução gradativa a partir de 2008, até chegar ao limite de 100.000 UFC/ml em 2011. Entretanto, até o momento, existem poucos dados sobre a situação dos produtores de leite em relação a esse aspecto. Este trabalho objetivou avaliar a qualidade microbiológica do leite cru refrigerado na fazenda, incluindo a presença de patógenos de interesse para a saúde do consumidor, e a associação entre a contaminação microbiana e os procedimentos de higienização dos equipamentos de ordenha e armazenamento do leite na propriedade.

\section{MATERIAL E MÉTODOS}

Durante um ano, coletaram-se três amostras de leite do tanque de refrigeração, em intervalo de quatro meses, de 24 rebanhos situados nas regiões Sudeste de Minas Gerais e Norte do estado do Rio de Janeiro. Nos rebanhos predominava gado mestiço Holandês-Zebu (50\%), seguido por animais da raça Holandesa (29\%), Jersey (17\%) e Pardo-Suíça (4\%). A média de produção de leite foi de $821 \pm 511 \mathrm{~kg} / \mathrm{dia}$, e o número médio de vacas em lactação de $58 \pm 34$. Em duas propriedades, as vacas em lactação eram mantidas em confinamento total (sistema free-stall) e nas demais adotava-se o sistema extensivo, em pasto. 
Todas as propriedades usavam a ordenha mecânica.

Cada amostra consistiu de cerca de $500 \mathrm{ml}$ de leite, retirados da parte superior e central do tanque, após a agitação programada por cinco minutos, utilizando-se um coletor de aço inoxidável e frascos esterilizados. Os frascos foram transportados em caixa isotérmica com gelo até o laboratório de microbiologia. Todas as amostras foram analisadas quanto à contagem padrão em placas, coliformes totais, presença de Staphylococcus aureus e Streptococcus agalactiae. Adicionalmente, em 14 das 24 propriedades, pesquisou-se a presença de Salmonella spp. e Listeria monocytogenes.

Para a contagem de mesófilos (contagem padrão), diluições apropriadas foram inoculadas em ágar padrão ${ }^{1}$ a $45^{\circ} \mathrm{C}$, e as placas foram incubadas a $32 \pm 1^{\circ} \mathrm{C}$ por $48 \pm 3$ horas (Marshall, 1992). Para a contagem de coliformes, utilizouse Petrifilm ${ }^{\mathrm{TM}}$ com incubação a $32 \pm 1^{\circ} \mathrm{C}$ por $24 \pm 2$ horas (Marshall, 1992).

$\mathrm{Na}$ pesquisa de patógenos contagiosos da mastite, as amostras de leite foram inoculadas em ágar sal manitol ${ }^{2}$ e ágar $\mathrm{TKT}^{2}$, seletivos para $S$. aureus e $S$. agalactiae, respectivamente. Após incubação de 48 horas, as colônias características típicas foram identificadas de acordo com Brito et al. (1998).

A pesquisa de L. monocytogenes foi realizada segundo Lait... (1990). Fez-se o enriquecimento seletivo transferindo-se $25 \mathrm{ml}$ de leite para $225 \mathrm{ml}$ do caldo de enriquecimento, para Listeria ${ }^{3}$, incubando-se a $30^{\circ} \mathrm{C} / 48 \mathrm{~h}$. Para o isolamento, utilizou-se o ágar $\mathrm{Oxford}^{1}$, com incubação das placas a $37^{\circ} \mathrm{C} \pm 1^{\circ} \mathrm{C}$, por 48 horas. Até cinco colônias típicas ou suspeitas foram transferidas para ágar triptona extrato de levedura ${ }^{1}$, e submetidas à confirmação bioquímica.

A pesquisa de Salmonella foi realizada segundo Andrews et al. (1998). No pré-enriquecimento, transferiram-se $25 \mathrm{ml}$ de leite para $225 \mathrm{ml}$ do caldo lactosado ${ }^{1}$, incubando-se a $35^{\circ} \mathrm{C}$ por 24 horas. Para o enriquecimento seletivo utilizaramse o caldo tetrationato ${ }^{1}$ e o caldo selenito-cistina ${ }^{1}$

\footnotetext{
${ }^{1}$ Difco - Becton Dickinson \& Company, EUA

${ }^{2}$ Merck - Darmstadt, Alemanha
}

e, para o isolamento, o ágar Hektoen ${ }^{1}$ e ágar xilose lisina desoxicolato ${ }^{1}$. Até seis colônias por placa com características do gênero Salmonella foram transferidas para os meios ágar tríplice açúcar-ferro $^{1}$ e ágar lisina-ferro ${ }^{2}$ para caracterização bioquímica preliminar.

Os procedimentos de higienização dos equipamentos de ordenha e armazenamento do leite foram avaliados in loco e documentados com auxílio de questionários considerando: 1) tipo de produtos químicos; 2) concentração e freqüência de uso dos detergentes e sanitizante; 3) procedimento de limpeza (manual ou automática).

Os resultados da contagem total padrão, contagem de coliformes totais, procedimentos de higienização do equipamento de ordenha $\mathrm{e}$ tanque de expansão foram classificados em três categorias. As categorias da contagem padrão foram: 1) até $100.000 \mathrm{UFC} / \mathrm{ml}$; 2) de $101.000 \mathrm{a}$ $500.000 \mathrm{UFC} / \mathrm{ml}$; 3) maior que $500.000 \mathrm{UFC} / \mathrm{ml}$. As categorias da contagem de coliformes totais foram: 1) até $100 \mathrm{UFC} / \mathrm{ml}$; 2) de 101 a $500 \mathrm{UFC} / \mathrm{ml}$; 3) maior que $500 \mathrm{UFC} / \mathrm{ml}$. Com relação aos procedimentos de higienização do equipamento de ordenha e tanque de expansão, os rebanhos foram classificados de acordo com o uso de detergentes alcalino e ácido e sanitizante da seguinte forma: 1) aplicação dos três produtos, 2) aplicação de pelo menos dois produtos, 3) aplicação de um produto ou nenhum. Aplicaram-se o teste do qui-quadrado (Sampaio, 2002) e a análise de correspondência pelo método de distribuição canônica (Souza et al., 2002).

\section{RESULTADOS E DISCUSSÃO}

As médias geométricas das três contagens de microrganismos mesófilos e coliformes totais são apresentadas na Tab. 1. Os resultados estão em ordem crescente, de acordo com a contagem padrão de mesófilos. Considerando a Instrução Normativa 51 (IN 51) do MAPA (Brasil, 2002), 20 rebanhos $(83 \%)$ atenderiam ao requisito de $<1,0 \times 10^{6} \mathrm{UFC} / \mathrm{ml}$ para contagem padrão, a vigorar entre 2005 e 2008, enquanto 19 (79\%) atenderiam ao padrão de $<7,5 \times 10^{5} \mathrm{UFC} / \mathrm{ml}$ do período de 2008/2011. Mais ainda, 11 (46\%) rebanhos atenderiam a exigência de $<1,0 \times 10^{5}$ $\mathrm{UFC} / \mathrm{ml}$ a partir de 2011. 
Tabela 1. Médias geométricas* da contagem de bactérias mesófilas (contagem-padrão) e coliformes totais em amostras de leite refrigerado de 24 rebanhos

\begin{tabular}{|c|c|c|}
\hline Rebanho & $\begin{array}{l}\text { Mesófílos } \\
(\mathrm{UFC} / \mathrm{ml})\end{array}$ & $\begin{array}{c}\text { Coliformes } \\
\text { (UFC/ml) }\end{array}$ \\
\hline 1 & 4.200 & 50 \\
\hline 2 & 6.700 & 210 \\
\hline 3 & 10.300 & 10 \\
\hline 4 & 17.500 & 160 \\
\hline 5 & 18.600 & 5 \\
\hline 6 & 27.500 & 180 \\
\hline 7 & 28.000 & 740 \\
\hline 8 & 55.400 & 110 \\
\hline 9 & 85.000 & 990 \\
\hline 10 & 88.200 & 100 \\
\hline 11 & 90.000 & 890 \\
\hline 12 & 109.000 & 91 \\
\hline 13 & 140.000 & 160 \\
\hline 14 & 145.000 & 350 \\
\hline 15 & 156.000 & 41 \\
\hline 16 & 198.000 & 3.035 \\
\hline 17 & 235.000 & 240 \\
\hline 18 & 291.000 & 4.700 \\
\hline 19 & 455.000 & 4.100 \\
\hline 20 & 961.000 & 2.200 \\
\hline 21 & 1.220 .000 & 6.000 \\
\hline 22 & 1.360 .000 & 1.400 \\
\hline 23 & 1.970 .000 & 23.000 \\
\hline 24 & 4.140 .000 & 290 \\
\hline
\end{tabular}

Nero et al. (2004) verificaram aderência ao requisito de $<10^{6} \mathrm{UFC} / \mathrm{ml}$ da IN 51 para o leite cru produzido em Viçosa-MG, Londrina-PR, Pelotas-RS e Botucatu-SP, de 80,8\%, 52,4\%, $42,0 \%$ e $32,0 \%$, respectivamente.

A maioria dos produtores necessita, portanto, canalizar esforços na melhoria das condições higiênicas durante a ordenha e o armazenamento do leite, e na sua refrigeração rápida na temperatura de $4^{\circ} \mathrm{C}$, para reduzir os níveis de contaminação microbiana e atender ao padrão definitivo para 2011.

O número de coliformes acima de $1,0 \times 10^{3} \mathrm{UFC} / \mathrm{ml}$ é indicativo de deficiências de higiene na produção de leite (Murphy, 1997). Contagem média de coliformes acima de $1,0 \times 10^{3}$ $\mathrm{UFC} / \mathrm{ml}$ foi verificada em sete rebanhos. Os coliformes são considerados indicadores de contaminação do ambiente e resíduos de fezes (Brito et al., 2002). Houve correlação positiva $(\mathrm{r}=0,61 ; \mathrm{P}<0,01)$ entre as contagens de mesófilos e de coliformes totais, indicando a importante contribuição da higiene do momento da ordenha para a contagem bacteriana total do leite.

Observou-se associação $(\mathrm{P}<0,05)$ entre as categorias da contagem padrão e a aplicação dos produtos de limpeza, tanto no equipamento de ordenha como no tanque de estocagem do leite nas propriedades. Os resultados da contagem padrão de até $100.000 \mathrm{UFC} / \mathrm{ml}$ estavam associados com procedimentos adequados de higienização do equipamento de ordenha e do tanque de estocagem de leite, com todos os produtos de limpeza recomendados: detergentes alcalino e ácido e sanitizante. As contagens entre 101.000 e $500.000 \mathrm{UFC} / \mathrm{ml}$ estavam associadas ao uso de pelo menos dois produtos de higienização (detergente alcalino e ácido, detergente alcalino e sanitizante, detergente ácido e sanitizante) e as contagens acima de $500.000 \mathrm{UFC} / \mathrm{ml}$ estavam associadas ao emprego de apenas um ou nenhum desses produtos na higienização (Tab. 2). Não houve associação $(\mathrm{P}>0,05)$ entre as categorias de contagem de coliformes totais e a aplicação dos produtos de limpeza no equipamento de ordenha e no tanque de estocagem do leite.

Tabela 2. Distribuição de freqüência da aplicação de produtos para higienização do equipamento de ordenha e tanque de estocagem do leite em 23 propriedades

\begin{tabular}{lcccc}
\hline Aplicação de detergente alcalino, & \multicolumn{2}{c}{ Equipamento de ordenha } & \multicolumn{2}{c}{ Tanque de estocagem } \\
\cline { 2 - 5 } detergente ácido e sanitizante & $\mathrm{n}$ & $\%$ & $\mathrm{n}$ & 7 \\
\hline Todos & 4 & 17,4 & 10 & 30,4 \\
Pelo menos dois produtos & 7 & 30,4 & 6 & 43,5 \\
Pelo menos um ou nenhum & 12 & 52,2 & 23 & 100,0 \\
Total & 23 & 100,0 & 26,1 \\
\hline
\end{tabular}


A presença de bactérias patogênicas no leite cru é uma preocupação de saúde pública, sendo um risco potencial para quem o consome diretamente ou na forma de seus derivados, e até para quem o manuseia. O leite cru contaminado pode ser, ainda, fonte de contaminação cruzada para os produtos lácteos processados, pela contaminação do ambiente na indústria. As freqüências de $S$. aureus, $S$. agalactiae, Salmonella spp. e $L$. monocytogenes no leite cru refrigerado são apresentadas na Tab. 3. Verifica-se que 23 dos $24(95,8 \%)$ rebanhos apresentaram, pelo menos, um dos patógenos, com predominância de $S$. aureus. Sua presença no leite é indicativo de infecção da glândula mamária e indica deficiências no controle da mastite. Sugere, ainda, risco de produção de enterotoxinas resistentes à pasteurização caso o leite não seja mantido à temperatura de refrigeração inferior a $7,2^{\circ} \mathrm{C}$ (FDA, 1992). A concentração de enterotoxina capaz de causar sintomas de intoxicação ocorre quando o número de $S$. aureus excede $10^{5}$ UFC/ml (FDA, 1992). Outro patógeno contagioso da mastite, o $S$. agalactiae, que tem o úbere infectado como único reservatório, ocorreu em 50\% dos rebanhos, quando o $S$. aureus também estava presente. $S$. agalactiae pode causar diversas infecções humanas, como meningite, pneumonia, endometriose, pielonefrite e artrite séptica (Flowers et al., 1992). A alta freqüência deles foi relatada em outros rebanhos da Zona da Mata e Campo das Vertentes, no estado de Minas Gerais, confirmando a prevalência diferenciada para os dois patógenos. Brito et al. (1999), em um estudo realizado com 48 rebanhos, isolaram S. aureus de 47 e $S$. agalactiae de 29. Brito et al. (2002) analisaram o leite dos fornecedores de um laticínio da Zona da Mata de Minas Gerais ao longo de um ano e encontraram $S$. aureus em $83,3 \%$ e $S$. agalactiae em $16,7 \%$ dos rebanhos.

Tabela 3. Freqüência de isolamento de Staphylococcus aureus, Streptococcus agalactiae, Salmonella spp. e Listeria monocytogenes em leite cru refrigerado, em rebanhos leiteiros de Minas Gerais

\begin{tabular}{lcccc}
\hline & \multicolumn{4}{c}{ Rebanhos com amostras de leite positivas / total de rebanhos } \\
\cline { 2 - 5 } & $\begin{array}{c}\text { Três amostras } \\
\text { positivo }\end{array}$ & $\begin{array}{c}\text { Duas amostras } \\
\text { positivo }\end{array}$ & $\begin{array}{c}\text { Uma amostra } \\
\text { positivo }\end{array}$ & $\begin{array}{c}\text { Total de } \\
\text { positivo }\end{array}$ \\
\hline S. aureus & $16 / 24$ & $2 / 24$ & $4 / 24$ & $22 / 24$ \\
& $(66,6 \%)$ & $(8,3 \%)$ & $(16,6 \%)$ & $(91,7 \%)$ \\
S. agalactiae & $6 / 24$ & $1 / 24$ & $5 / 24$ & $12 / 24$ \\
& $(25 \%)$ & $(4,2 \%)$ & $(20,8 \%)$ & $(50 \%)$ \\
\hline
\end{tabular}

Patógenos da mastite causam alterações no processo de síntese do leite dentro da glândula mamária, podendo afetar sua qualidade (Auldist e Hubble, 1998). O processo inflamatório resulta no aumento do número de células somáticas, que é associado a problemas de sabor e aroma no leite e seus derivados, menor rendimento na fabricação de queijos e perda de gordura e caseína no soro (Audist e Hublle, 1998; Ma et al., 2000). Como sua disseminação no rebanho se dá principalmente durante a ordenha, pelas mãos dos ordenhadores e equipamentos de ordenha, a adoção de procedimentos higiênicos nessa fase é essencial para o controle efetivo da mastite e para reduzir o número de microrganismos no leite.

Salmonella spp. e L. monocytogenes não foram isolados nas amostras de leite analisadas. Outros autores relataram a ausência de $L$. monocytogenes em leite cru produzido em várias regiões do Brasil (Destro et al., 1991; Oliveira et al., 1994; Nero et al., 2003). Dados da literatura indicam freqüências de isolamento de $L$. monocytogenes em leite cru no Brasil variando de 0 a 16,7\% (Destro et al. 1991; Moura et al. 1993; Nero et al. 2003; Silva et al., 2003).

Surtos e casos esporádicos de infecção por Salmonella spp. ou por L. monocytogenes têm sido associados ao leite e derivados, sendo as causas o consumo de leite cru ou seus derivados, pasteurização inadequada ou contaminação pósprocessamento (Boor, 1997).

\section{CONCLUSÕES}

O leite obtido por ordenha mecânica e refrigerado a $4^{\circ} \mathrm{C}$, em algumas propriedades rurais, apresentou qualidade microbiológica satisfatória quando comparada aos padrões 
exigidos internacionalmente. A adoção de procedimentos de limpeza completa de equipamentos de ordenha e estocagem do leite contribuiu para a redução da contagem de mesófilos no leite. A alta prevalência de patógenos contagiosos da mastite aponta a necessidade de implementação de programas de controle dessa doença e a ausência de Salmonella sp. e L. monocytogenes indica que, nos rebanhos avaliados, esses patógenos não constituíram perigo evidente no leite cru.

\section{AGRADECIMENTOS}

A Marcos Aurélio Souto Silva, pela atuação nos exames microbiológicos.

\section{REFERÊNCIAS BIBLIOGRÁFICAS}

ANDREWS, W.H.; JUNE, G.A.; SHERROD, P. et al. Salmonella. In: FOOD AND DRUG ADMINISTRATION, (Ed). Bacteriological Analytical Manual. 8.ed. Gaithersburg: AOAC International, 1998. p.5.01-5.20.

AUDIST, M.J.; HUBLLE, I.B. Effects of mastitis on raw milk and dairy products. Austr. $J$. Dairy Technol., v.53, p.28-36, 1998.

BOOR, K.J. Pathogenic microorganisms of concern to the dairy industry. Dairy Food Environ. Sanit., v.17, p.714-717, 1997.

BRASIL. Ministério da Agricultura, Pecuária e Abastecimento. Instrução Normativa no. 051, de 18 de setembro de 2002. Diário Oficial da União, Brasília, 20 set. 2002. Seção 1, p.13-22.

BRITO, M.A.V.P.; BRITO, J.R.F.; PORTUGAL, J.A.B. Identificação de contaminantes bacterianos no leite cru de tanques de refrigeração. Rev. Inst. Lat. Cândido Tostes, v.57, p.47-52, 2002.

BRITO, M.A.V.P.; BRITO, J.R.F.; RIBEIRO, M.T. et al. Padrão de infecção intramamária em rebanhos leiteiros: exame de todos os quartos mamários das vacas em lactação. Arq. Bras. Med. Vet. Zootec., v.51, p.129-135, 1999.

BRITO, M.A.V.P.; BRITO, J.R.F.; SOUZA, H.M. et al. Avaliação da sensibilidade da cultura de leite do tanque para isolamento de agentes contagiosos da mastite bovina. Pesq. Vet. Bras., v.18, p.39-44, 1998.

CHAMPAGNE, C.P.; LAING, R.R.; ROY, D. et al. Psycrhrotrops in dairy products: their effects and their control. Crit. Rev. Food Sci. Nutr., v.34, p.1-30, 1994.

CHEN, L.; DANIEL, R.M.; COOLBEAR, T. Detection and impact of protease and lipase in milk powders. Int. Dairy J., v.13, p.255-275, 2003.

DESTRO, M.T.; SERRANO, A.M.; KABUKI, D.Y. Isolation of Listeria species from some Brazilian meat and dairy products. Food Control, v.2, p.110-112, 1991.

FLOWERS, R.S.; ANDREWS, W.; DONNELLY, C.W. et al. Pathogens in milk and milk products. In: MARSHALL, R.T. (Ed.). Standard methods for the examination of dairy products. 16.ed. Washington, DC: American Public Health Association, 1992. p.103-212.

FOOD and drug administration. Foodborne pathogenic microorganisms and natural toxins. Center for Food Safety and Applied Nutrition. Rockville, Maryland, 1992. p. 12-16.

FROEDER, E.; PINHEIRO, A.J.R.; BRANDÃO, S.C.C. Variação da qualidade microbiológica do leite cru tipo $\mathrm{C}$ da Região de Viçosa. Rev. Inst. Lat. Cândido Tostes, v.40, p.55-68, 1985.

HAYES, M.C.; BOOR, K. Raw milk and fluid milk products. In: MARTH, E. H.; STEELE, J.L. (Eds.). Applied dairy microbiology, 2.ed. New York: Marcel Dekker, 2001. p.59-76.

HICKS, C.L.; ALLAUDDIN, M.; LANGLOIS, B.E.; O'LEARY, J. Psychrotrophic bacteria reduce cheese yield. J. Food Protec., v.45, p.331-334, 1982.

LAIT et produits laitiers. Recherche de Listeria monocytogenes. Brussel: Norme FIL 143: 1990, 1990. 8p.

MA, Y.; RYAN, C.; BARBANO, D.M. et al. Effects of somatic cell count on quality and shelf-life of pasteurized fluid milk. J. Dairy Sci., v.83, p.264-267, 2000.

MARSHALL, R.T. Standard methods for the examination of dairy products. 16.ed. Washington, DC: American Public Health Association, 1992. 546p. 
MOURA, S.M.; DESTRO, M.T.; FRANCO, B.D.G.M. Incidence of Listeria species in raw and pasteurized milk produced in São Paulo, Brazil. Int. J. Food Microbiol., v.19, p.229-237, 1993.

MUIR, D.D. The shelf-life of dairy products: 1 . Factors influencing raw milk and fresh products. J. Soc. Dairy Technol., v.49, p. 24-50, 1996.

MURPHY, S. Raw milk bacteria tests: standard plate count, preliminary incubation counts, lab pasteurized count, and coliform count. What do they mean for your farm? In: NATIONAL MASTITIS COUNCIL REGIONAL MEETING, Syracuse. Proceedings... Syracuse, 1997. p.34-42

NERO, L.A.; FRANCO, B.D.G.M.; MATTOS, M.R. et al. Leite cru de quatro regiões leiteiras brasileiras: perspectivas de atendimento dos requisitos microbiológicos estabelecidos pela instrução normativa $\mathrm{n}^{\mathrm{0}} 51$. In: DURR, J.W.; CARVALHO, M.P.; SANTOS, M.V. (Eds.). $O$ compromisso com a qualidade do leite no Brasil. Passo Fundo, RS: UFP Editora, 2004. p.189-194.

NERO, L.A.; MATTOS, M.R.; BELOTI, V. et al. Risk characterization in raw milk: Prevalence of Listeria monocytogenes, Salmonella spp. and chemical residues. In: CONGRESSO BRASILEIRO DE MICROBIOLOGIA, 22., 2003, Florianópolis. Anais... Florianópolis, 2003. (CD rom).

OLIVEIRA, A.N.; MESQUITA, A.J.; NUNES, I.A. et al. Ocorrência de bactérias do gênero Listeria em leite cru e pasteurizado em Goiânia, Goiás. CONGRESSO NACIONAL DE LATICÍNIOS, 22., Juiz de Fora, MG. Anais... Juiz de Fora, 1994. p.35-39.

SAMPAIO, I.B.M. Estatística aplicada a experimentação animal. Belo Horizonte: Fundação de Ensino e Pesquisa em Medicina Veterinária e Zootecnia, 2002. 221p.

SILVA, I.M.M.; ALMEIDA, R.C.C.; ALVES, M.A.O. et al. Occurrence of Listeria spp. in critical control points and the environment of Minas Frescal cheese processing. Int. J. Food Microbiol., v.81, p.241-248, 2003.

SOUZA, G.N.; BRITO, J.R.F.; BASTOS, R.R. et al. Avaliação de associações e similaridades em epidemiologia veterinária por meio da análise de correspondência. Arq. Bras. Med. Vet. Zootec., v.54, p.539-542, 2002. 